\title{
Numerical analysis of the circulation variability in the Zadar channel area (east Adriatic)
}

\author{
G. Lončar ${ }^{1}$, G. Beg Paklar ${ }^{2}$ \& V. Andročec ${ }^{1}$ \\ ${ }^{I}$ Faculty of Civil Engineering, Water Research Department, \\ University of Zagreb, Croatia \\ ${ }^{2}$ Institute of Oceanography and Fisheries, Split, Croatia
}

\begin{abstract}
Three numerical hydrodynamic models, ROMS, POM and MIKE 3 FM, were used to simulate circulation variability in the middle Adriatic coastal area. ROMS and POM models were used to perform a year-long simulation of the Adriatic circulation with the spatial resolution of approximately $2 \mathrm{~km}$. Temperature, salinity and sea level fields, obtained by the ROMS model, were used for the initial and boundary conditions in the MIKE 3 FM local domain covering the channel area off Zadar. A similar area was covered with the POM local domain nested within the shelf and Adriatic-scale POM models using threedimensional velocity, temperature and salinity fields, as well as two-dimensional sea level fields from coarser resolution grids. Current fields obtained by both modelling systems are in agreement with the ADCP measurements performed in the area of the local models. During winter northwestward currents dominate in the surface layer, while in the lower layers of the channel topographically controlled gyres can be observed. Both measurements and numerical simulations indicate current reversal to southeastern direction in the coastal area off Zadar during summer.

Keywords: hydrodynamic models, ROMS, POM, MIKE 3 FM, wind-induced currents, tidal currents, ADCP measurements, Adriatic Sea, Zadar.
\end{abstract}

\section{Introduction}

Croatian coast of the Adriatic Sea has complicated coastline and bathymetry with more than 1200 islands, innumerable channels, bays and inlets. Such complex geometry severely influences the coastal circulation mainly driven by 
meteorological and hydrological forcings. Although occasionally in some parts of the eastern coastal strip tidal currents and buoyancy-driven circulation can be important, in general these current components tend to be secondary in comparison with wind-induced motions [1].

Physical processes in the middle Adriatic coastal area were studied within several national and international projects. The Zadar and Pašman channel area was investigated during early nineties due to the planned implementation of the public sewage system. Temperature, salinity and current measurements were made during two campaigns, the first one in June/July and the second one during August/September 2004, focused on the near coastal area. Although the main goal of Vilibić and Orlić [2] investigation were surface seiches and internal Kelvin waves in the Zadar and Pašman channel, they also calculated and discussed tidal, wind-induced and residual circulation. Tidal dynamics in the wider Zadar area is particularly interesting because of its close position to the Adriatic semidiurnal amphydromic point [3]. Wind-driven currents in the channel are predominantly baroclinic during summer and two-layer response was clearly observed during strong sirocco episode. Similar result describing wind influence on the currents was obtained by Leder et al. [4]. Residual currents were oppositely directed during two campaigns, and the reversal was related to the meteorological activity. The interesting feature of the residual dynamics was cyclonic and anticyclonic gyres, controlled by topography. Three-dimensional model [5] developed for the area off Zadar agreed with measurements and moreover indicated that vertically averaged currents at the basin mouth formed an anticyclonic gyre during a bora episode and a cyclonic gyre when sirocco wind blows.

Measurements in the open sea area off Zadar and Pašman channel were performed within international project 'East Adriatic Coastal Experiment' (EACE). Two maxima detected in the East Adriatic Current, the first one during winter and the second one during spring, were related to the water and heat airsea fluxes, respectively [6]. Wind-induced currents were barotropic during winter and baroclinic during spring due to different stratification and stability conditions.

This paper gives insight into the numerical modelling of the circulation in the channel area off Zadar (Fig. 1) made within 'The Adriatic Sea monitoring program' during 2007 and 2008 [7]. Since the objective of the Program was the development of an efficient monitoring system and supporting models for the Adriatic coastal waters, besides modelling, Program also comprised extensive oceanographic measurements within the Croatian territorial waters. Two modelling systems were developed during the Program: the first one consisted of the Regional Ocean Modeling System (ROMS) [8, 9] and MIKE 3 FM [10] models, while the other one was made of nested Princeton Ocean Model (POM) [11] models. In the following second section of the paper the basic characteristics of both modelling systems will be described. The third section presents the results of the modelling and their comparison with measurements, while final fourth section brings brief discussion and conclusions. 


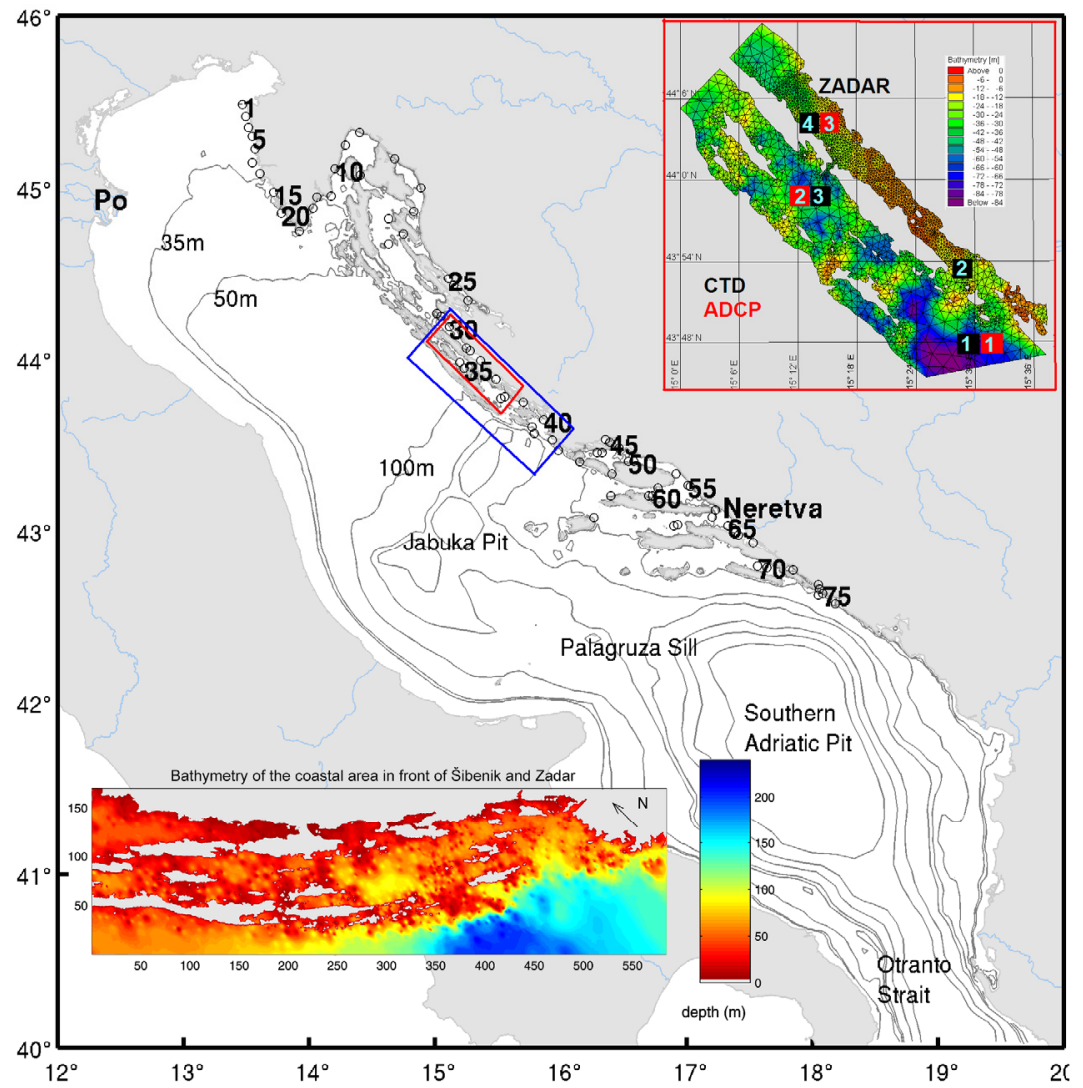

Figure 1: $\quad$ Spatial domain of the Adriatic-scale POM and ROMS models with MIKE 3 FM and POM local spatial domain. Monitoring sites are denoted with circles.

\section{Numerical models implementation}

Circulation variability in the middle Adriatic coastal area was reproduced with two nested modelling systems. The first one was made of the Adriatic-scale ROMS model and MIKE 3 FM applied for the local domain off Zadar. The second modelling system was made of three nested POM-based models: the Adriatic-scale model, shelf model and local POM model. POM and ROMS models are finite difference, terrain-following, primitive equation models. On the other hand, MIKE 3 FM is a finite volume model with sigma vertical component. In the application for the channel area off Zadar MIKE 3 FM uses unstructured horizontal grid with resolution ranging from $2 \mathrm{~km}$ at the outer part of the domain up to $150 \mathrm{~m}$ close to the coast.

As a first step in the modelling, the Adriatic Sea dynamics has been simulated with two three-dimensional nonlinear sigma models: POM and ROMS for the 
period between November 2007 and October 2008. Both models had almost the same setup which allowed for a reliable comparison between their results. In a year-long simulation numerical models were forced with atmospheric, river and tidal forcing. Atmospheric forcing for the ocean models was calculated from the output fields of the meteorological mesoscale model ALADIN [12] having $8 \mathrm{~km}$ horizontal resolution and 3 hour resolution in time using standard bulk formulation. The ALADIN model has been used for operational purposes at the Meteorological and Hydrological Service of Croatia and, in particular, it has been applied for studying the mesoscale environment in which severe winds in the Adriatic region occur $[13,14]$. Used (Croatian version) of the operational ALADIN is run on a domain which covers the Adriatic region together with the surrounding orography of the Alps, the Dinaric Alps and the Apennines [15]. Influence of 48 Adriatic rivers in the ROMS and POM domains has been defined through the climatological data according to Raichich [16] with the exception of Po and Neretva Rivers where hourly averaged measured values of discharges and temperatures were utilized. Tidal function was applied on the southern open boundaries of both models at the Otranto Straight for denivelation and transport using seven harmonic constituents - M2, S2, N2, K1, O1 and $\mathrm{P} 1$, while radiation condition was applied for the three-dimensional current field. Both Adriaticscale models had horizontal resolution of approximately $2 \mathrm{~km}$ while along vertical 22 and 30 sigma layers were defined for POM and ROMS, respectively (Table 1). POM and ROMS models used also the same initial conditions. Both models were initialized with mean summer fields of temperature and salinity on standard oceanographic levels from Dartmouth Adriatic Data Base (DADB) [17].

Table 1: $\quad$ Implemented numerical models and numerical simulations.

\begin{tabular}{|c|c|c|c|}
\hline Model & Period & $\begin{array}{l}\text { Horizontal } \\
\text { resolution }\end{array}$ & $\begin{array}{l}\text { Vertical } \\
\text { resolution }\end{array}$ \\
\hline $\begin{array}{c}\text { Adriatic- } \\
\text { scale POM }\end{array}$ & $\begin{array}{c}15 \text { October } 2007-15 \text { October } \\
2008\end{array}$ & $2.5 \mathrm{~km}$ & $\begin{array}{c}22 \text { sigma } \\
\text { layers }\end{array}$ \\
\hline Middle & 17 February - 13 March 2008 & \multirow[t]{2}{*}{$1 \mathrm{~km}$} & \multirow{2}{*}{$\begin{array}{c}16 \text { sigma } \\
\text { layers }\end{array}$} \\
\hline POM & 17 July - 16 August 2008 & & \\
\hline \multirow[t]{2}{*}{ Local POM } & 17 February - 13 March 2008 & \multirow[t]{2}{*}{$200 \mathrm{~m}$} & \multirow{2}{*}{$\begin{array}{l}16 \text { sigma } \\
\text { layers }\end{array}$} \\
\hline & 17 July - 16 August 2008 & & \\
\hline $\begin{array}{c}\text { Adriatic- } \\
\text { scale ROMS }\end{array}$ & $\begin{array}{l}15 \text { October } 2007-15 \text { October } \\
2008\end{array}$ & $2 \mathrm{~km}$ & $\begin{array}{l}30 \text { sigma } \\
\text { layers }\end{array}$ \\
\hline \multirow[t]{2}{*}{ MIKE 3 FM } & 17 February - 13 March 2008 & \multirow[t]{2}{*}{$150-2000 \mathrm{~m}$} & \multirow{2}{*}{$\begin{array}{l}20 \text { sigma } \\
\text { layers }\end{array}$} \\
\hline & 17 July - 16 August 2008 & & \\
\hline
\end{tabular}

The results obtained from Adriatic-scale models were used to define open boundary conditions for the fine resolution models embedded along the eastern coast using one-way offline nesting procedure. Temperature, salinity and surface elevations calculated with ROMS model were extracted, interpolated and implemented on the open boundaries of the MIKE 3 FM model. On the other 
hand, open boundary conditions of the local POM model are defined through direct nesting with inclusion of all hydrodynamic fields: temperature, salinity, current velocity and surface elevation using procedure described by Zavatareli and Pinardi [18]. Initial conditions for the local models were defined according to the corresponding Adriatic model results. Atmospheric and river forcings in the fine resolution models were defined in the manner described for Adriatic models. Simulations covered the periods $17 / 2 / 08-13 / 3 / 08$ and $17 / 7 / 0-16 / 8 / 08$ by both of the local models. The spatial resolutions used in MIKE 3 FM and POM shelf and local models together with simulation periods are shown in Table 1.

During the modelling periods oceanographic parameters were measured within territorial water of the Republic of Croatia. Oceanographic sites were divided into groups in accordance with measured parameters: current meter sites and CTD sites (Fig. 1). Measurements undertaken on CTD verticals were used for calibration and validation of ROMS and POM Adriatic models, while currents measured at ADCP sites were used for the comparison with local models results.

\section{Modelling results and comparison with measurements}

Surface mean monthly current fields obtained by the POM model show significant resemblance with the corresponding fields from ROMS. Although considerable variability can be observed in the modelled current fields, they also indicate some common features in accordance with well-known characteristics of the Adriatic-scale circulation. General circulation is cyclonic with several imbedded, mostly cyclonic gyres. Two cyclonic gyres are around the main pits - South Adriatic and Jabuka Pit, and one can be observed in the northernmost part of the Adriatic. Current fields in the winter period resemble bora induced current fields [19], indicating bora wind as an important driving mechanism for the Adriatic general circulation. Current intensities during summer decreased and numerous small-scale eddies appeared. South Adriatic cyclonic gyre is present in all monthly current fields but with variable intensities. Cyclonic gyre above the South Adriatic Pit is a well-known characteristic of the Adriatic circulation and it is supposed to be topographically controlled by the South Adriatic Pit and Palagruža Sill. The main difference between POM and ROMS monthly averaged fields is manifested through the current intensity, mainly in jet currents. They are attached to the outer boundary of the Croatian outer islands, as well as through the intensity of the cyclonic South Adriatic gyre.

Calibration of ROMS and POM Adriatic models is referenced to the results of the CTD measurements at the positions of the oceanographic stations 1-75 (Fig. 1). Comparison of the modelling results with measurements during winter simulation period at the oceanographic stations 1-4 (Zadar area, Fig. 1) is presented in Fig. 2. Generally, deviations of the POM model results from the temperatures measured in March 2008 are less than $1{ }^{\circ} \mathrm{C}$ and both modelled and measured temperature profiles shows vertical homogeneity typical for the winter season. Maximal model deviations from the salinity measurements are $1 \mathrm{psu}$ in the surface layer of all stations, while modelled and measured salinities are in 
better accordance in the bottom layer. Modelled temperature and salinity profiles for the summer period show stronger departures from the measured values if compared to the winter profiles, with lower agreement in the vertical structure and higher absolute differences. Simulated values of both temperatures and salinities are in agreement with their realistic values for summer in the coastal Adriatic area, but stronger homogeneity in the model results is suggesting too strong vertical mixing in the POM model. Generally, better agreement between modelled and measured thermohaline properties is obtained in the northern Adriatic in comparison to the middle and southern coastal areas. High correlation between measured and modelled temperature and salinity profiles is obtained also with ROMS model, particularly in simulations with more realistic initial and open boundary files from operational model [20].
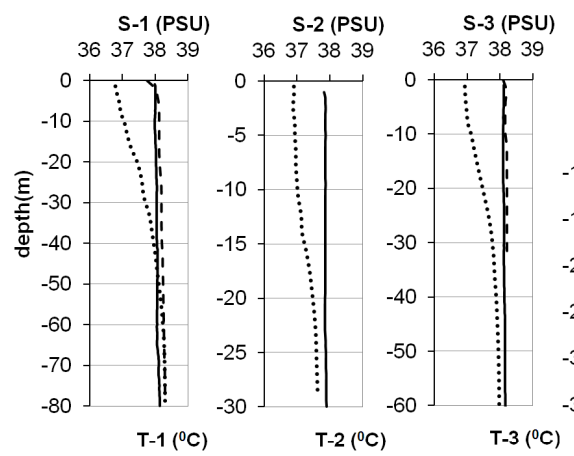

S-4 (PSU)
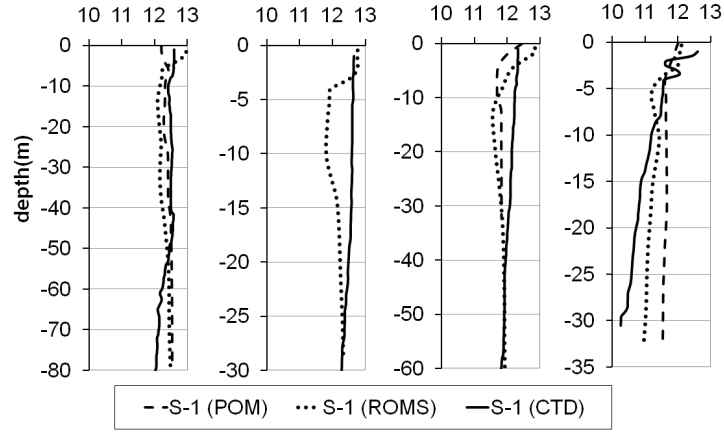

Figure 2: Comparison of measured (CTD) and model (ROMS, POM) verticals for T, S (13 March 2008).

Both local models reproduced almost homogeneous northwestern flow in the surface layer during winter (Figs. 3 and 4). Current intensities in the lower layers are reduced and in the outer part of the POM domain flow is northwestward while in the channel topographically-controlled gyres are present. Similar structures cannot be seen in the MIKE 3 FM results. Modelled current vectors agree well with measured monthly means directed toward northwest [7]. Modelled and measured current components indicate the importance of the tidal signal in the 
a)

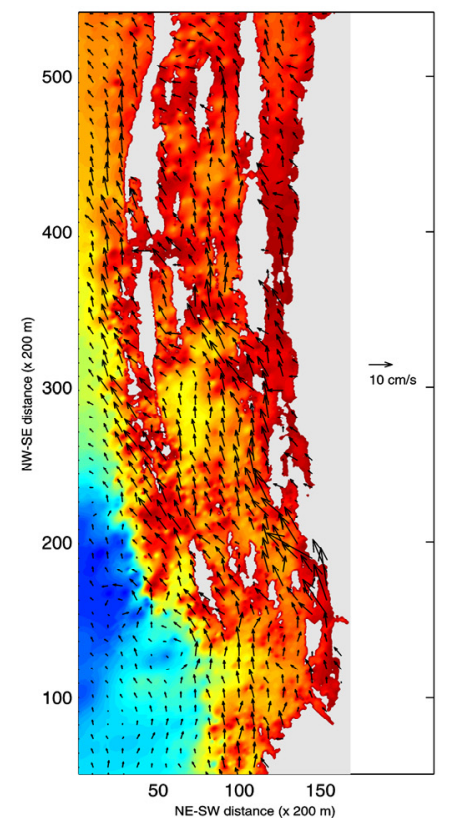

b)

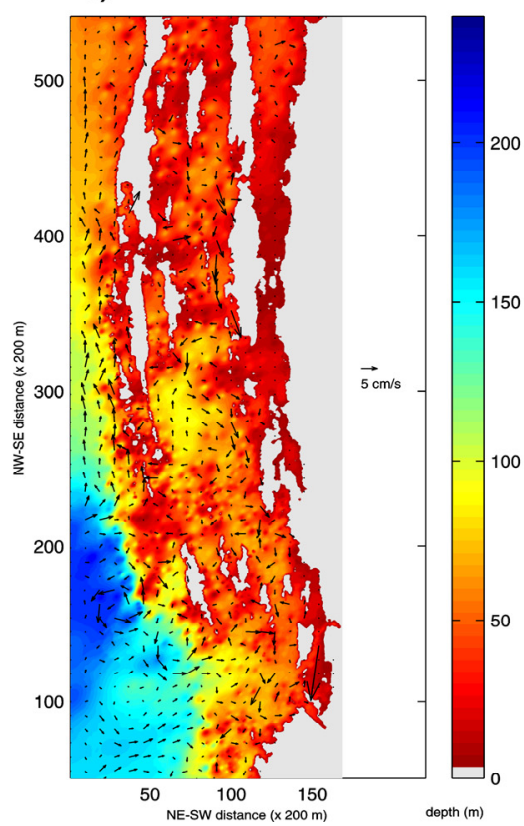

Figure 3: Current fields in the Zadar-Šibenik area at 8 (a) and $26 \mathrm{~m}$ (b) during winter obtained by local POM model.
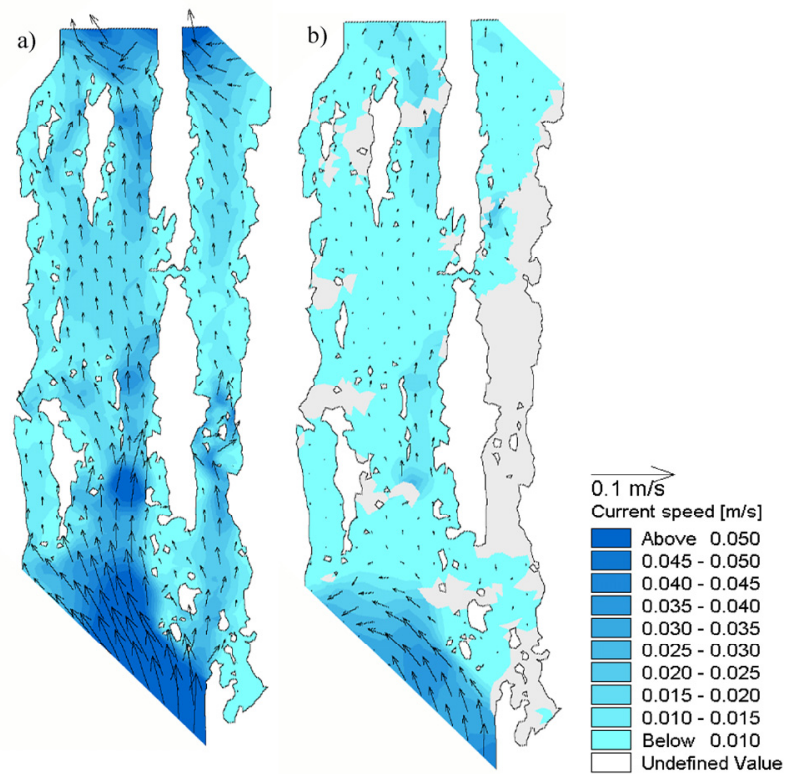

Figure 4: Current fields in the Zadar-Šibenik area at 8 (a) and $26 \mathrm{~m}$ (b) during winter obtained by MIKE 3 FM model. 


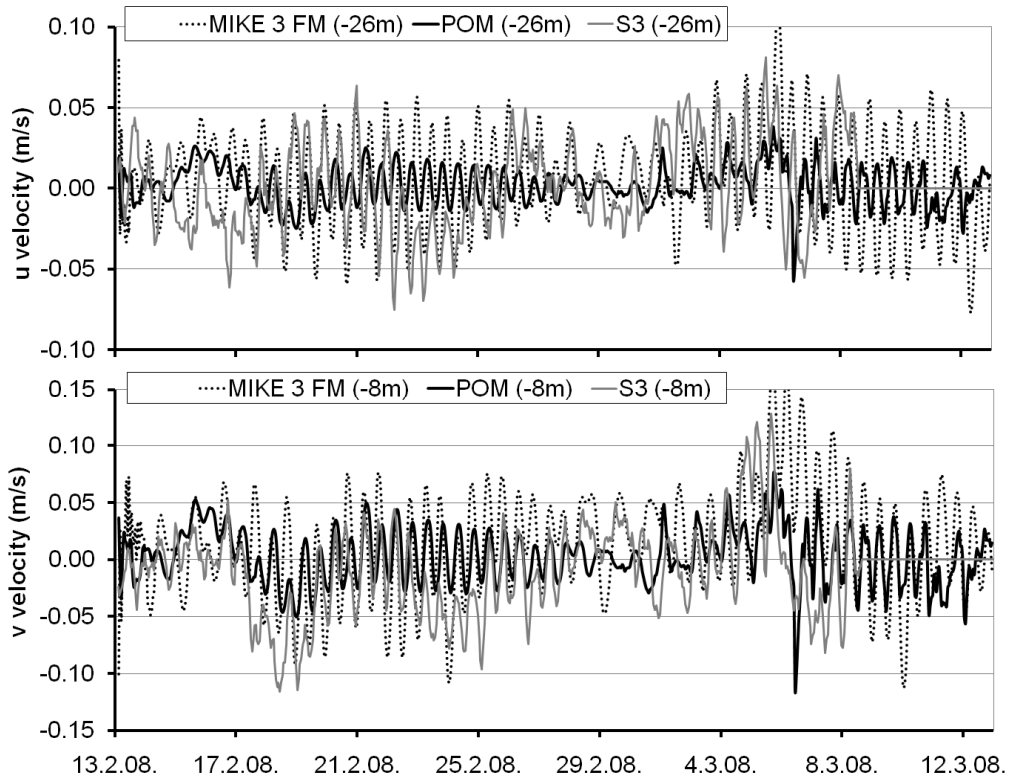

Figure 5: Comparison of the measured and modelled hourly averaged current velocity components at the ADCP site $\mathrm{S} 3$ at the depth of $8 \mathrm{~m}$.

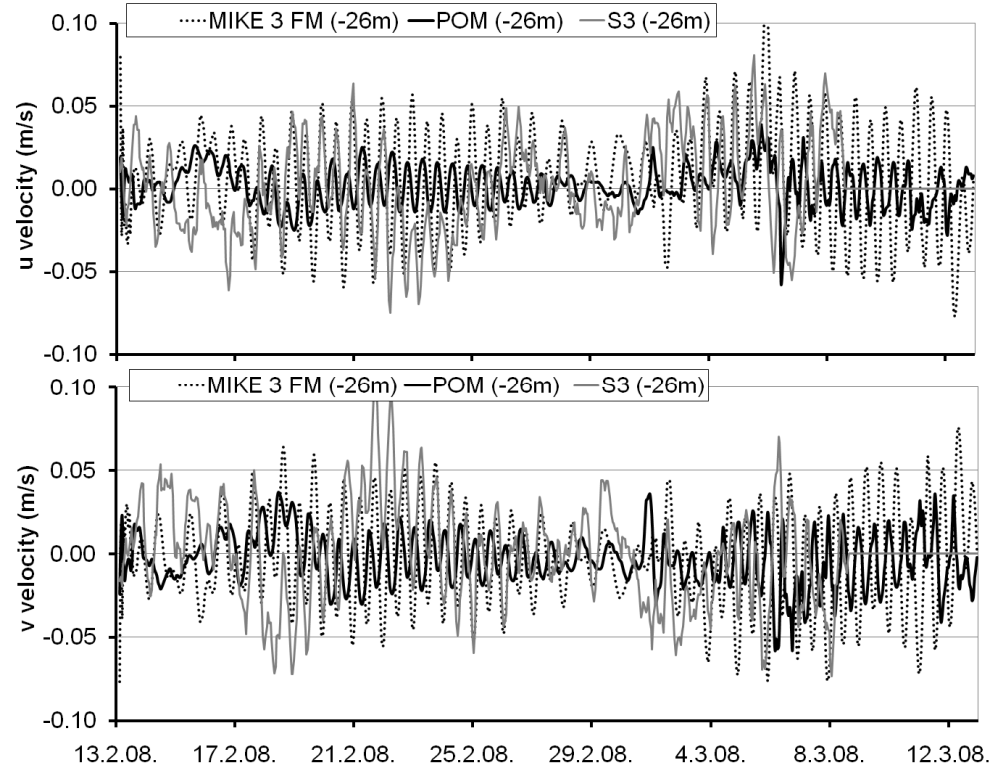

Figure 6: Comparison of the measured and modelled hourly averaged current velocity components at the ADCP site S3 at the depth of $26 \mathrm{~m}$. 
studied channel area during winter (Figs. 5 and 6). POM modelled current component time series show well reproduced bora influence at ADCP station 3. Bora started on 5 March and induced downwind current in the surface layer.

a)

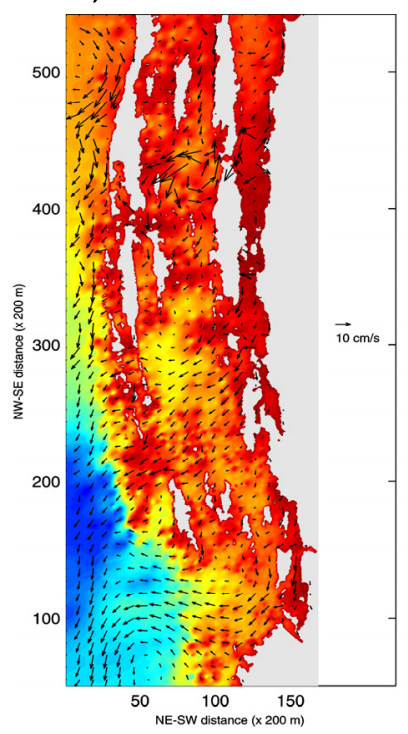

b)

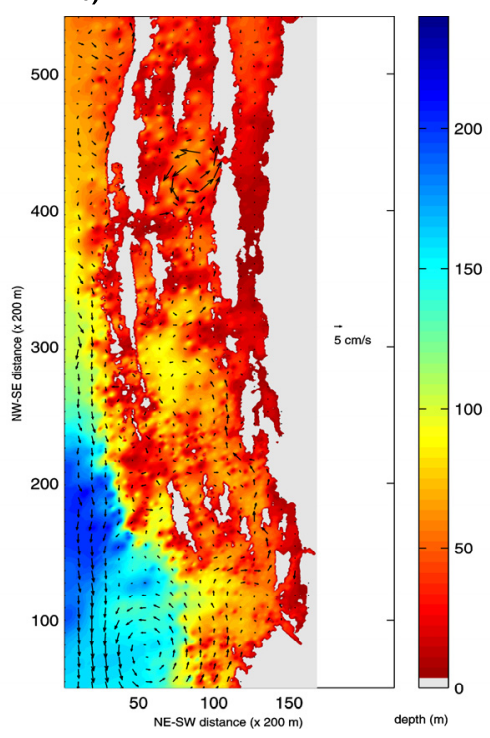

Figure 7: Current fields in the Zadar-Šibenik area at 8 (a) and $26 \mathrm{~m}$ (b) during summer obtained by local POM model.
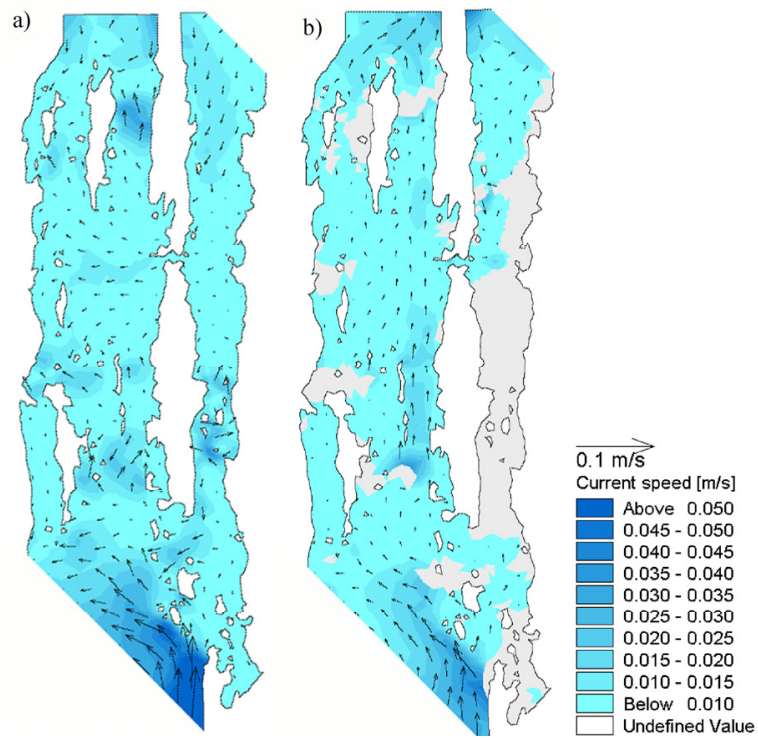

Figure 8: Current fields in the Zadar-Šibenik area at 8 (a) and $26 \mathrm{~m}$ (b) during summer obtained by MIKE 3 FM model. 
Dominant southeastern flow can be observed in the outer part of the POM model domain during summer simulation period. MIKE 3 FM reproduced southeastern flow in front of the mainland. Occurrence of the southeastern flow in the modelled fields is in agreement with measurements. Mean monthly current vector obtained at ADCP station 2 is also of southeastern direction during August 2008 and it is related to the intensive winds from northeast and northwest. As well as during winter, tidal signal is important component of the current field and it is well reproduced by both models.

\section{Conclusions}

Sea temperature, salinity and current fields in the eastern Adriatic coastal region are resolved through implementation of numerical models ROMS, POM and MIKE 3 FM. ROMS and POM were used for the hydrodynamic analysis on the whole Adriatic area with the spatial resolution of approximately $2 \mathrm{~km}$. The results of that analysis were used to generate the initial and boundary conditions for nested local domains covering the part of the middle Adriatic channel system in the vicinity of the city of Zadar.

In the scope of the work presented in this article, ROMS and POM models applied on the Adriatic scale both had the same setup. The comparison of results revealed that both models could successfully reproduce basic characteristics of the Adriatic circulation: global cyclonal flow with series of smaller, mostly cyclonal vortexes. Furthermore, current fields modelled by ROMS and POM indicate major similarity on a monthly scale, though in some areas differences appear. Main difference between POM and ROMS monthly averaged current field is manifested through the current velocity intensities, mainly in jet currents that are attached to the outer boundary of the Croatian outer islands, as well as through the intensities of the cyclonic South Adriatic gyre. Since unfortunately current measurements in the open sea area were not performed during periods of the simulations, modelled circulations could not be verified and it was impossible to say which model gave better results on the Adriatic scale. Evaluation of the Adriatic models was made with CTD measurements. Modelled temperature and salinity profiles are of acceptable accuracy with errors increasing from north to south Adriatic and during heating season.

Validation of the local models POM and MIKE 3 FM with results of the ADCP measurements indicate acceptable agreement for both modelling systems. During winter season modelled currents in the outer part of the POM domain are northwestward along the whole water column. In the channel area surface currents are also northwesteward during winter simulation period, while topographically controlled gyres can be observed in the lower layers of the POM model results. Both measurements and numerical simulations indicate current reversal to southeastern direction in the coastal area off Zadar during summer. Moreover, current measurements and model results point to the dominance of the tidal signal off Zadar during both winter and summer.

Increased accuracy of both nested modelling systems could be attained by using higher resolution of the atmospheric forcing, implementation of the 
realistic river discharges instead of the used climatological values and by solving the open boundary conditions with nesting of the Adriatic scale models with one of the operational Mediterranean systems.

\section{References}

[1] Orlić, M., Croatian coastal waters. In Physical Oceanography of the Adriatic Sea: Past, Present and Future, ed. Cushman-Roisin, B., Gačić, M., Poulain, P.M. and Artegiani, A., Kluwer Academic Publishers: Dordrecht, Boston, London, pp. 189-214, 2001.

[2] Vilibić, I. and Orlić, M., Surface Seiches and Internal Kelvin Waves Observed Off Zadar (East Adriatic). Estuarine, Coastal and Shelf Science, 48, pp. 124-136, 1999.

[3] Polli, S., Le propagazione delle mare nell' Adriatico. Atti del IX Convegno dell'Associazione Geofisica Italiana, Rome, pp. 1-11, 1960.

[4] Leder, N., Beg Paklar, G., Gržetić, Z., Smirčić, A. and Vilibić, I., Winddriven currents in the channel area: An example of the channels zadarski kanal and pašmanski kanal (East Adriatic area). Rapport du 35e Congrès de la CIESMM, 35(1), pp. 166-167, 1998.

[5] Bone, M., Development of a non-linear levels model and its application to bora-driven circulation on the Adriatic shelf. Estuarine, Coastal and Shelf Science, 37, pp. 475-496, 1993.

[6] Orlić, M., Dadić, V., Grbec, B., Leder, N., Marki, A., Matić, F., Mihanović, H., Beg Paklar, G., Pasarić, M., Pasarić, Z. and Vilibić, I., Wintertime buoyancy forcing, changing seawater properties and two different circulation systems produced in the Adriatic. Journal of Geophysical Research, 112(C3), C03S07, doi: 10.1029/2005JC003271, 2007.

[7] Andročec, V., Beg Paklar, G., Dadić, V., Djakovac, T., Grbec, B., Janeković, I., Krstulović, N., Kušpilić, G., Leder, N., Lončar, G., Marasović, I., Precali, R. and Šolić, M., The Adriatic Sea Monitoring Program - Final Report, MZOPUG, Zagreb, pp. 623, 2009.

[8] Schepethin, A. and McWilliams, J., The Regional Ocean Modeling System (ROMS): A split explicit, free-surface, topography-following coordinates ocean model. Ocean Modelling, 9, pp. 347-404, 2005.

[9] Wilkin, J.L., Arango, H.G., Haidvogel, D.B., Lichtenwalner, C.S., S.C. Glenn, S.C., and Hedstrom, K.S., A regional ocean modeling system for the long term ecosystem observatory. Journal of Geophysical Research, 110(6), pp. 1-13, 2005.

[10] DHI, Mike 3 flow model: hydrodynamic module - scientific documentation, DHI Software 2007, Denmark, 2007.

[11] Blumberg, A.F., and Mellor, G.L., A description of three-dimensional coastal ocean circulation model. In: Three Dimensional Coastal Ocean Models, ed. Heaps, N.S., Coastal and Estuarine Science 4, American Geophysical union, Washington, D.C., pp. 1-16, 1987. 
[12] Cordoneanu, E., and Geleyn, J.F., Application to local circulation above the Carpathian-Black Sea area of a NWP-type meso-scale mode. Contributions to Atmospheric Physics, 71, pp. 191-212, 1998.

[13] Brzović, N., Factors affecting the Adriatic cyclone and associated windstorms, Contributions to Atmospheric Physics, 72, pp. 51-65, 1999.

[14] Brzović, N., and Strelec-Mahović, N., Cyclonic activity and severe jugo in the Adriatic, Physics and Chemistry of the Earth (B), 24, pp. 653-657, 1999.

[15] Ivatek-Šahdan, S., and Tudor, M., Use of high-resolution dynamical adaptation in operational suite and research impact studies, Meteorologische Zeitschrift, 13, pp. 99-108, 2004.

[16] Raicich, F., Note on the Flow Rates of the Adriatic Rivers, IST-CNR Technical Report, RF 02/94, pp. 1-6, 1994.

[17] Galos, C., Seasonal circulation in the Adriatic Sea, M.S. thesis, Dartmouth Coll., Hanover, N.H., pp 127, 2000.

[18] Zavatarelli, M., and Pinardi, N., The Adriatic Sea modeling system: A nested approach. Annales Geophysicae, 21, pp. 345-364, 2003.

[19] Beg Paklar, G., Isakov, V., Koračin, D., Kourafalou, V. and Orlić, M., A case study of bora-driven flow and density changes on the Adriatic shelf (January 1987), Continental Shelf Research, 21, pp. 1751-1783, 2001.

[20] Janeković, I., Dutour Sikirić, M., Tomažić, I., and Kuzmić, M.: Hindcasting the Adriatic Sea surface temperature and salinity: A recent modeling experience, Geofizika, 27, pp. 85-100, 2010. 